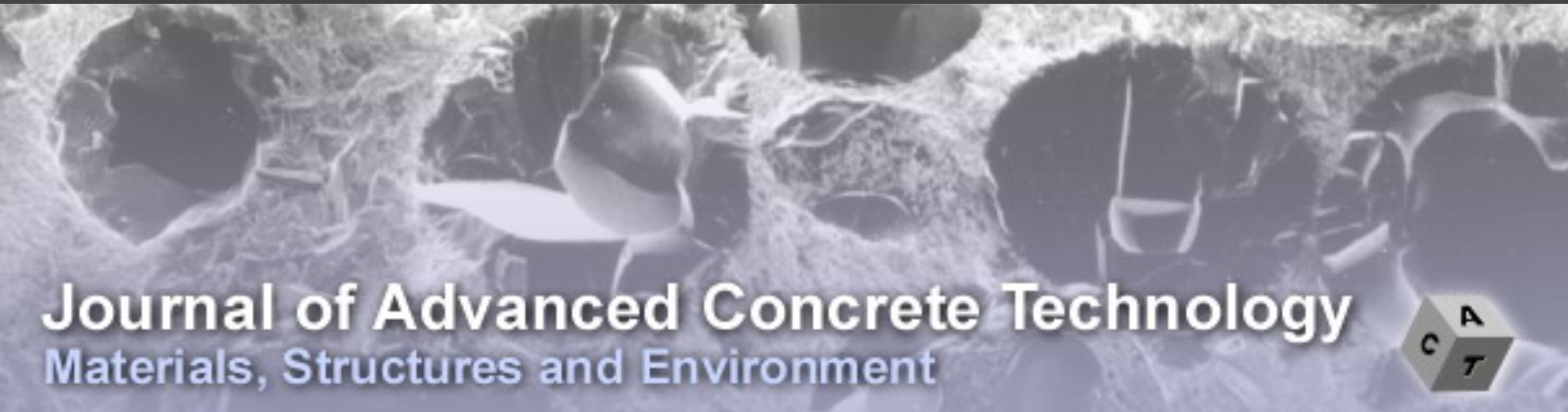

\title{
Early age hydration, microstructure and micromechanical properties of cement paste modified with polymeric vesicles
}

Jie Hu, Dessi A. Koleva, Yuwei Ma, Erik Schlangen, Klaas van Breugel

Journal of Advanced Concrete Technology, volume 11 (2013 ), pp. 291-300

\section{Related Papers Click to Download full PDF!}

Influence of Shrinkage-Reducing Admixtures on Early-Age Properties of Cement Pastes

Dale P. Bentz

Journal of Advanced Concrete Technology, volume 4 (2006), pp. 423-429

Early Age Stress Development, Relaxation, and Cracking in Restrained Low W/B Ultrafine Fly Ash Mortars Akhter B Hossain, Anushka Fonseka, Herb Bullock

Journal of Advanced Concrete Technology, volume 6 (2008), pp. 261-271

Effects of PFA and GGBS on Early-Ages Engineering Properties of Portland Cement Systems Xiangming Zhou, Joel R. Slater, Stuart E. Wavell, Olayinka Oladiran

Journal of Advanced Concrete Technology, volume 10 (2012), pp. 74-85

Click to Submit your Papers 


\title{
Early Age Hydration, Microstructure and Micromechanical Properties of Cement Paste Modified with Polymeric Vesicles
}

\author{
Jie $\mathrm{Hu}^{1}$, Dessi A. Koleva ${ }^{2}$, Yuwei $\mathrm{Ma}^{3}$, Erik Schlangen ${ }^{4}$ and Klaas van Breugel ${ }^{4}$
}

\begin{abstract}
The influence of limited concentration, of 0.025 wt.\% per cement weight, poly (ethylene oxide) -block -polystyrene vesicles on the hydration process, microstructure and micromechanical properties of cement paste at early hydration age of maximum 7 days are discussed. Isothermal calorimetry and non-evaporable water content tests indicate that the admixed vesicles have no apparent influence on the process of cement hydration, but affect microstructural properties. Whereas nitrogen adsorption tests reveal that the gel pore structure of the vesicles-modified matrix is almost identical to the vesicles-free one, mercury intrusion porosimetry proves refined capillary porosity and reduced total porosity in the presence of admixed vesicles. Nano-indentation supports the above observations and indicates that the admixed vesicles act as nucleation sites, leading to a more uniform distribution of low density hydration products.
\end{abstract}

\section{Introduction}

Polymers are widely applied in petroleum engineering, civil engineering and construction applications (Merlin et al. 2005) . With regard to cement based materials, polymers are applied as superplasticizers, air-entraining admixtures, shrinkage- reducing admixtures, etc. (Folliard and Berke 1997; Zhang et al. 2001). The general aim of these applications is improving material properties, e.g. workability, setting time, water requirement and mechanical strength (Aitcin and Neville 2003; Jansen et al. 2012; Young 1972), consequently producing high-strength and high-performance concretes (Jansen et al. 2012; Li et al. 2005; Neville and Aitcin 1998). The influence of admixed polymers on the properties of cement-based materials is reported to be mainly related to their dispersion ability via increasing repulsive forces and hindering the coagulation and sedimentation of the cement particles by introducing electrostatic and/or steric repulsion (Jansen et al. 2012; Mollah et al. 2000). The reported mechanisms are generally commented with regard to the molecular structure and adsorption characteristics of the investigated polymeric additions

${ }^{1}$ Associate Professor, School of Materials Science and Engineering, South China University of Technology, Guangzhou, China.

${ }^{2}$ Assistant Professor, Faculty of Civil Engineering \& Geosciences, Materials \& Environment, TU Delft, Delft, The Netherlands.

E-mail: d.a.koleva@tudelft.nl

${ }^{3} \mathrm{PhD}$ student, Faculty of Civil Engineering \& Geosciences, Materials \& Environment, TU Delft, Delft, The Netherlands.

${ }^{4}$ Professor, Faculty of Civil Engineering \& Geosciences, Materials \& Environment, TU Delft, Delft, The Netherlands.
(Uchikawa et al. 1997). It is also known that admixed polymers generally influence cement hydration to a significant extent, consequently affect the morphology and microstructure of cement-based materials (Chandra and Flodin 1987; Mollah et al. 2000; Young 1972).

More recently, block copolymers have been widely investigated (Park et al. 2003) because of the specifics of their highly ordered structures (Hadjichristidis et al. 2002; Hamley 1998) and the possibility to develop and design nano-particles with desired size, morphology and composition (Krishnamoorti et al. 1998). Unique properties in selective solvents can be obtained with amphiphilic copolymers, consisting of both hydrophilic and hydrophobic blocks (Girod et al. 2008). When the environmental conditions (temperature, $\mathrm{pH}$, ionic strength) change, the copolymers self-assemble into micelles, vesicles and/or other supramolecular structures (Gil and Hudson 2004). Therefore, amphiphilic copolymers are widely used in many industrial applications, e.g. templates for the preparation of inorganic nano-particles (Gorna et al. 2007; Sun and Gutmann 2004), crystal growth modifiers (Rudloff et al. 2002), electrolyte components for rechargeable batteries (Singh et al. 2007), "vehicles" of active substances release (Khanal and Nakashima 2005; Kojima et al. 2008), etc.

The application of amphiphilic copolymers in the form of nano-architectures for cement-based materials is to our best knowledge not reported. In our previous research, the influence of polymeric micelles and vesicles (with a hydrodynamic radius of $50 \mathrm{~nm}$ and $220 \mathrm{~nm}$ ) respectively on the corrosion performance of reinforced concrete was investigated (Hu et al. 2012b, 2011, 2012c). Micelles are polymeric, self-assembled nano-architectures with amphiphilic properties in our case, whereas vesicles are nano-sacs, that enclose a volume, containing water or chosen substances. Both micelles and vesicles were prepared from polyethylene oxide-b-polystyrene (PEO-b-PS) diblock copolymer. 
Initial tests in simulated pore solution ( $\mathrm{Hu}$ et al. 2011) and reinforced mortar in the presence of micelles ( $\mathrm{Hu}$ et al. 2012 b) proved that corrosion initiation was delayed on one hand and chloride binding capacity of the mortar was increased on the other. Further investigations on admixed vesicles, and especially Ca-containing ones, where saturated $\mathrm{Ca}(\mathrm{OH})_{2}$ solution was pre-reserved in their core, (Hu et al. 2012c) indicated "self-healing" effect of the corrosion damage in the reinforcement: after corrosion initiation, the steel corrosion resistance was significantly increased and corrosion propagation on the steel reinforcement was halted. The most plausible mechanism is initially related to increased chloride binding capacity of the bulk matrix and further calcium release from the vesicles on anodic locations (active spots) i.e. formation of Ca-substituted iron oxides/hydroxides layers with increased corrosion resistance was observed. The trigger of altered vesicles morphology and core release is modified pore solution chemistry in the presence of chlorides and altered ions/water/oxygen balance on the steel surface within and after corrosion initiation. All together, these processes lead to repair or "self-healing" of the steel surface layer.

Considering the complicated nature of both micelles and vesicles and their effect on permeability, Cl-binding capacity, etc. of a cement system, their influence on bulk matrix properties only, when no steel reinforcement or corrosion phenomena are involved, is logically of interest and deserves investigation for substantiated reasoning behind the postulated "repair" or "self-healing" effects. The effect of micelles, i.e. reduced porosity and water permeability, has been previously reported ( $\mathrm{Hu}$ et al. 2012a). These results were a positive outcome if steel corrosion in reinforced cement-based systems is considered. Corrosion initiation and corrosion propagation depend on the material properties of a reinforced cement-based system, e.g. if the rate of chlorides or $\mathrm{CO}_{2}$ penetration is limited or none, steel is (generally) in a passive state. Since corrosion initiation depends on the cement matrix permeability and diffusivity, which in turn determine the rate of penetration of aggressive substances, the early age hydration mechanisms are of great importance. To this end, the objective of this study is to clarify the influence of vesicles (empty i.e. not Ca-bearing ones) on material properties: hydration rate and microstructure of cement-based materials at early hydration age. The hydration process was evaluated both by isothermal calorimetry and non-evaporable water content tests; the pore structure of the cement matrix was studied by nitrogen adsorption (for the gel pore structure) and mercury intrusion porosimetry (for the capillary pore structure). Further, nano indentation was conducted to investigate the influence of admixed vesicles on the formation and distribution of hydration products.

\section{Materials and methods}

\subsection{Materials \\ 2.1.1 Vesicles}

The vesicles used in this study were prepared from $\mathrm{PEO}_{113}-\mathrm{b}-\mathrm{PS}_{780}$ di-block copolymer (the molecule structure of the copolymer is presented in Fig. 1). The copolymer was synthesized by atom transfer radical polymerization (ATRP), employing the macroinitiator technique (Hu et al. 2012b; Matyjaszewski and Xia 2001). The vesicles solution was prepared by dialysis: $0.5 \mathrm{~g} \mathrm{PEO}_{113}$-PS780 diblock copolymer was dissolved in $800 \mathrm{ml} \mathrm{1,4-dioxane}$ and $200 \mathrm{ml}$ deionized water were added drop-wise. The vesicles gradually formed at the interface between dioxane and deionized water. The solution was then transferred to regenerated cellulose tubular membrane (MWCO 12,000 g/mol) and dialyzed against deionized water to remove dioxane. The vesicles concentration in solution was $0.5 \mathrm{~g} / \mathrm{l}$. The morphology of $\mathrm{PEO}_{113}-\mathrm{b}-\mathrm{PS}_{780}$ vesicles is spherical, presenting a membrane of an outer hydrophilic - PEO and an inner, hydrophobic - PS part. The hydrodynamic radius, determined by dynamic light scattering (DLS) measurement, is about $220 \mathrm{~nm}$ (Hu et al. 2012d) (details about the vesicles preparation can be found in (Hu et al. 2012c)).

\subsubsection{Cement paste specimens}

In this study, Ordinary Portland Cement OPC CEM I 42.5 N (ENCI, Table 1) was used to prepare the cement paste specimens; the water-to-cement $(\mathrm{w} / \mathrm{c})$ ratio was 0.5 .

The samples for mercury intrusion porosimetry (MIP), $\mathrm{N}_{2}$ adsorption and nano indentation tests were prepared in plastic bottles. After casting, the samples were rotated for 24 hours to avoid sedimentation and then cured in sealed conditions at room temperature. After curing for 1 , 3 and 7 days, standard sample preparation for ceasing cement hydration was employed: the samples were submerged in liquid nitrogen and further placed in a vacuum freeze-dryer at $-28{ }^{\circ} \mathrm{C}$ (water sublimation) until achieving a constant weight. For isothermal calorimetry

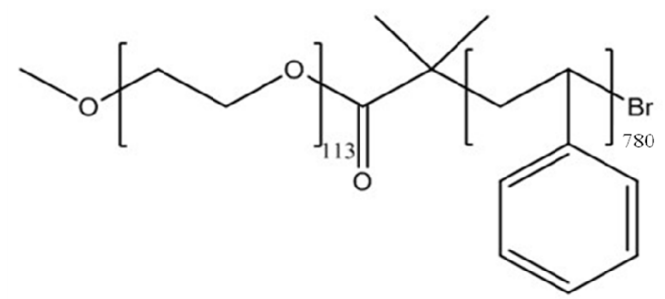

Fig.1 Molecule structure of $\mathrm{PEO}_{113}-\mathrm{PS}_{780}$ diblock copolymer used in this study.

Table 1 Chemical compositions of OPC CEM I $42.5 \mathrm{~N}$ (ENCI, NL).

\begin{tabular}{|c|c|c|c|c|c|c|c|c|c|c|c|}
\hline \multicolumn{12}{|c|}{ Chemical compositions of OPC CEM I $42.5 \mathrm{~N}$} \\
\hline Oxide & $\mathrm{CaO}$ & $\mathrm{SiO}_{2}$ & $\mathrm{Al}_{2} \mathrm{O}_{3}$ & $\mathrm{SO}_{3}$ & $\mathrm{Fe}_{2} \mathrm{O}_{3}$ & $\mathrm{MgO}$ & $\mathrm{Na}_{2} \mathrm{O}$ & $\mathrm{K}_{2} \mathrm{O}$ & $\mathrm{TiO}_{2}$ & $\mathrm{P}_{2} \mathrm{O}_{5}$ & $\mathrm{Mn}_{3} \mathrm{O}_{4}$ \\
\hline Weight $(\%)$ & 64.4 & 20.36 & 4.96 & 2.57 & 3.17 & 2.09 & 0.14 & 0.64 & 0.35 & 0.18 & 0.14 \\
\hline
\end{tabular}


and non-evaporable water content tests, parallel groups of cement paste (same mixtures) were prepared (procedures' details are described further below). Two main groups were investigated in this study: group "OPC" as control, vesicles-free specimens cast with tap water and group "OPCv" as vesicles-containing specimens cast with the as produced vesicles' solution instead of tap water. The vesicles concentration was thus $0.025 \mathrm{wt}$. \% (by weight of dry cement) in cement paste for specimen OPCv.

\subsection{Methods}

\subsubsection{Hydration rate and hydration degree}

Isothermal calorimetry was performed on 3 replicates for each specimen using a micro-calorimeter (TEM Air 314) at $20^{\circ} \mathrm{C}$. Before the tests, the mixing tools and materials were stored at $20{ }^{\circ} \mathrm{C}$ in the same room for 24 hours. Cement was mixed with tap water (for specimen OPC) or vesicles' solution (for specimen OPCv) within $60 \pm 5$ seconds; then about $10 \mathrm{~g}$ cement paste was carefully poured into glass calorimeter ampoules (the rest of the cement paste was tightly sealed in plastic bottles for the measurement of non-evaporable water content). The whole procedure was completed within $3 \mathrm{~min}$. The heat flow and the cumulative heat release were recorded until $168 \mathrm{~h}$ (7 days). The rate of hydration was measured as power $(\mathrm{mW})$ and was normalized per gram of cement.

Non-evaporable water content $\left(W_{n / c}\right)$ : The hydration degree of the cement paste was obtained by determining the non-evaporable water content $\left(\mathrm{W}_{\mathrm{n} / \mathrm{c}}\right) . \mathrm{W}_{\mathrm{n} / \mathrm{c}}$ is defined as the weight loss per gram of original cement paste, measured between the temperatures of $105{ }^{\circ} \mathrm{C}$ and $1000{ }^{\circ} \mathrm{C}$ (Copeland and Hayes 1953). At each hydration age ( 1 day, 3 days and 7 days), the samples were ground to powders and then 3 replicates were dried in an oven at $105^{\circ} \mathrm{C}$ for at least 12 hours; the samples were then ignited at $1000{ }^{\circ} \mathrm{C}$ in a furnace for 3 hours (details about the procedure and calculation are as described in Copeland and Hayes (1953) and Molina (1992).

\subsubsection{Microstructure evaluation}

Nitrogen adsorption: For nitrogen adsorption tests, the samples were first crushed into small pieces (with a weight of less than $0.05 \mathrm{~g}$ ). The crushed samples were weighted and placed in a glass tube, the latter positioned in the chamber of Germini VII 2390 Surface Area Analyzer. The glass tube was evacuated first, and then filled with pure nitrogen. $p$ and $p_{0}$ were defined as the nitrogen pressure in the tube and the saturated pressure respectively. During the measurement, the adsorption amounts of nitrogen at different relative pressures $\left(p / p_{0}\right)$ from 0.05 to 0.95 were recorded. The pore size distribution was determined by Barrett-Joyner-Halenda (BJH) method (Barrett et al. 1951).

Mercury intrusion porosimetry (MIP), using Micrometritics Poresizer 9320 (with pressure limits from 0.0036 to $210 \mathrm{MPa}$ ) was performed. The measurement was conducted in two stages: the first stage was at low pressure, from 0 to $0.0036 \mathrm{MPa}$ and the second stage was at high pressure running from 0.0036 to $210 \mathrm{MPa}$, followed by an extrusion running from 210 to $0.14 \mathrm{MPa}$. The surface tension of mercury was $484 \times 10^{-3} \mathrm{~N} / \mathrm{m}$ and the contact angle was $130^{\circ}$. According to Washburn equation (Washburn 1921), the pore size range detected in this study is from $350 \mu \mathrm{m}$ to $0.007 \mu \mathrm{m}$. There were 2 replicates for both nitrogen adsorption and MIP tests.

Nano indentation: Before nano indentation tests (performed for samples at hydration age of 7 days only), the samples were ground with silicon carbide papers (fineness in the range from 320 to 4000) and then polished with diamond pastes of sizes $6,3,1$ and $0.25 \mu \mathrm{m}$ to obtain a very flat and smooth surface. After polishing, the specimens were cleaned in an ultrasonic bath. Nano indentation is a method providing information on micromechanical properties via indentation load and displacement measurements, including distribution of un-hydrated particles, calcium silicate hydrate $(\mathrm{CSH})$ and calcium hydroxide $(\mathrm{CH})$ at micro and sub-micro scale. Fig. 2 presents a typical data curve of indentation load-displacement as recorded in this study. The Continues Stiffness Method (CSM Method) developed by Oliver \& Pharr (Oliver and Pharr 2004) was used for the analyses of the results and the average E-modulus was determined in the loading range between 200 and $800 \mathrm{~nm}$ depths.

Agilent Nano Indenter G200 equipped with a pyramid-shaped Berkovich diamond indenter probe was applied to determine the micromechanical properties of cement paste. Nano indentation mapping was used to investigate the local elastic modulus properties between two adjacent un-hydrated particles. Before the indentation, two adjacent cement grains were located and marked via ESEM. The investigated matrix covered an area of at least $40 \times 340 \mu \mathrm{m}^{2}$ with a minimum of 175 indents. The selected indent spacing was $10 \mu \mathrm{m}$. At least 6 locations were measured for each specimen.

ESEM and EDX analysis: An environmental SEM (ESEM Philips XL30), in backscattered electrons (BSE) mode (working distance of $10 \mathrm{~mm}$, accelerating voltage at $20 \mathrm{keV}$ ), combined with energy dispersive X-ray analysis (EDX) was employed for morphology observa-

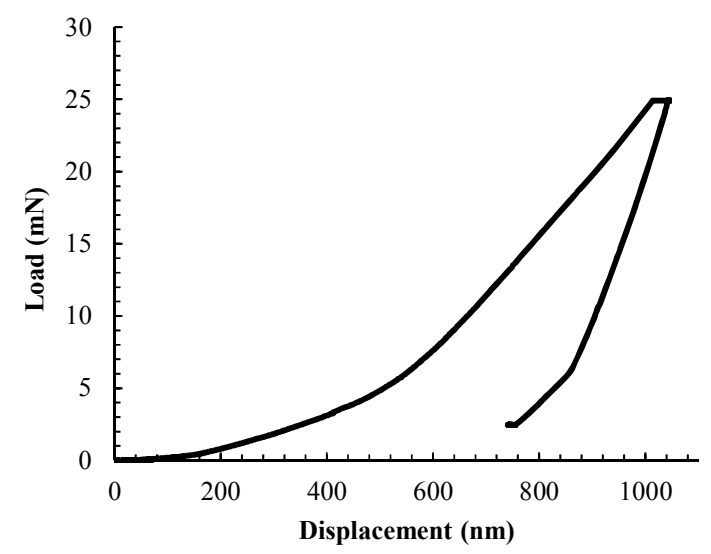

Fig.2 Typical data curve of indentation load-displacement. 
tion and qualitative and semi-quantitative analysis of the cement matrix. These enable an assessment and correlation of the nano indentation results, the morphology of the corresponding surface and the composition of relevant (indented) phases.

\section{Results and discussions}

\subsection{Hydration process of cement paste in the presence of admixed vesicles}

The rate of heat release and the cumulative heat for both specimens during the first $168 \mathrm{~h}$ are presented in Fig. 3. It can be observed that the admixed vesicles slightly decelerated the hydration rate of tri-calcium silicate $\left(\mathrm{C}_{3} \mathrm{~S}\right.$, corresponding to the main peak in Fig. 3(a)) by about 36 minutes. Similarly, the total heat release for the modified cement paste was also slightly reduced by the admixed vesicles: at 7 days (168 h) hydration age, the cumulative heat release was $315.69 \mathrm{~J} / \mathrm{g}$ for specimen OPC and $306.35 \mathrm{~J} / \mathrm{g}$ for specimen $\mathrm{OPCV}$ respectively. The isothermal calorimetry results are in line with those for degree of hydration, determined by the non-evaporable water content $\left(\mathrm{W}_{\mathrm{n} / \mathrm{c}}\right)$, shown in Fig. 4.

The degree of hydration for both vesicles-free (OPC) and vesicles containing ( $\mathrm{OPCv}$ ) cement pastes is very similar at each hydration age, Fig. 4: e.g. at 7 days, for specimen OPC - $49.53 \%$, for specimen OPCv - $49.43 \%$ are relevant. These results are in contrast to the previously recorded ones for micelles-modified cement paste (Hu et al. 2012a). For completeness, a comparison of the influence of admixed micelles and vesicles on the hydration process of cement paste at 7 days hydration age is presented in Table 2. Compared to vesicles, although again minimal difference, but yet opposite trends of slightly increased degree of hydration for the micelles-modified matrix was observed i.e. at the age of 7 days, the cumulative heat release and hydration degree of micelles-modified specimens was $314.92 \mathrm{~J} / \mathrm{g}$ and $50.80 \pm 0.55 \%$, compared to 315.69 and $49.27 \pm 0.98 \%$ for the non-modified matrix. These results are as expected to a certain extent, considering the larger surface area of micelles $(50 \mathrm{~nm})$, compared to the hereby investigated vesicles $(220 \mathrm{~nm})$ and therefore the possibility of more pronounced "nucleation sites effect" in the former, rather than in the latter case. Additionally, some reports on retardation of early hydration of cement paste due to admixed PEO-containing polymers (normally used as superplasticizers for cement-based materials) need to be also considered (Sakai et al. 2006; Winnefeld et al. 2007) as contributing factors. The retardation effects are reported to be mainly relevant to the hydration of $\mathrm{C}_{3} \mathrm{~S}$
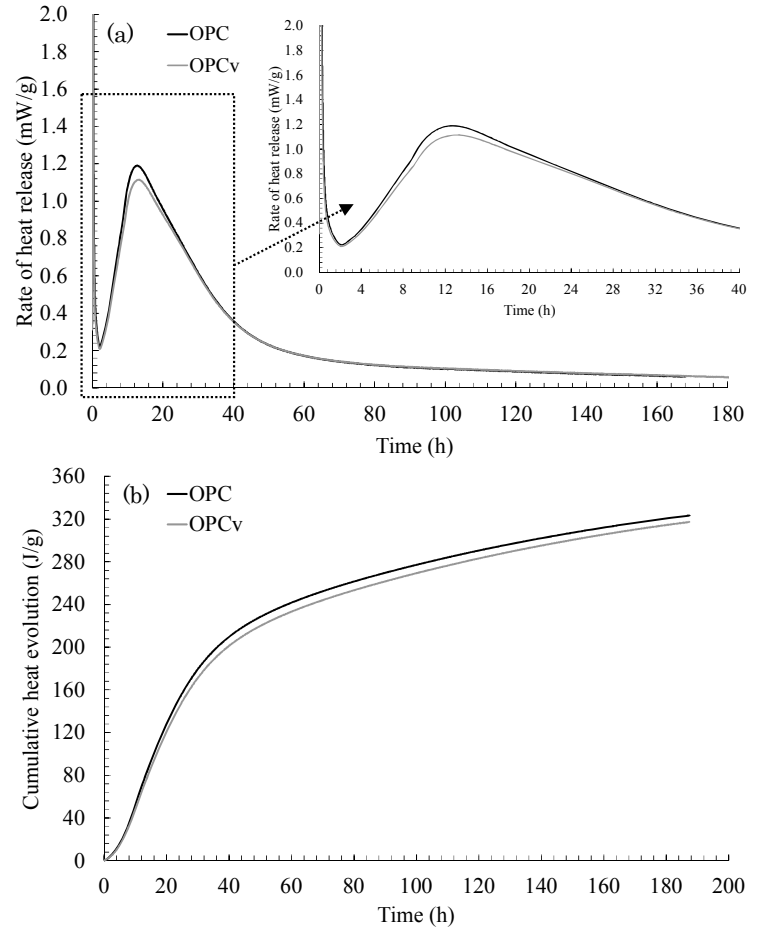

Fig.3 (a) Hydration rate and (b) Cumulative heat evolution of the cement paste in the absence (specimen OPC) and presence (specimen OPC $v$ ) of admixed vesicles respectively

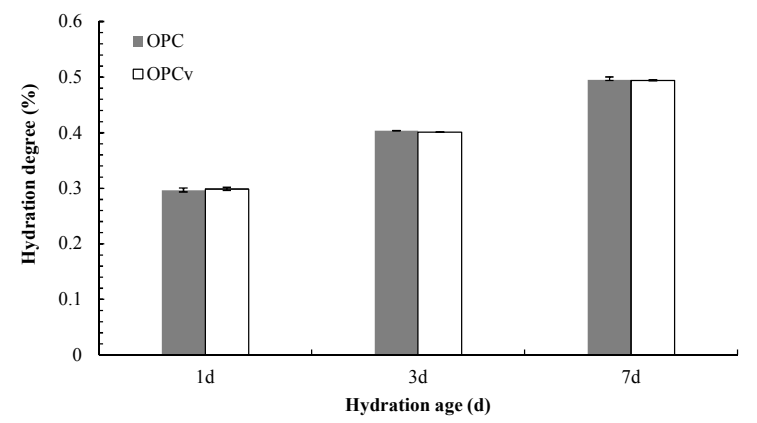

Fig.4 Hydration degree of the cement paste determined by non-evaporable water content.

(Lothenbach et al. 2007; Pourchet et al.; Winnefeld et al. 2007) and the proposed mechanisms (Gu et al. 1994; Jansen et al. 2012; Mollah et al. 2000) can be summarized as: (1) polymers adsorption on the surface of cement grains, hindering the diffusion of water and $\mathrm{Ca}^{2+}$ ions at the cement grain/solution interface; (2) impeded growth of hydrate phases due to the presence of polymers; (3) dispersive ability and effect of the polymers which alter the growth kinetics and morphology of the hydration products. These effects are not necessarily

Table 2 Comparison of the influence of micelles and vesicle on the hydration process of cement paste at the hydration age of 7 days.

\begin{tabular}{|c|c|c|}
\hline Mixing water & Accumulative heat release (J/g) & Hydration degree (\%) \\
\hline Tap water & 315.69 & 49.53 \\
\hline Micelles solution & 314.92 & 50.80 \\
\hline Vesicles solution & 306.35 & 49.43 \\
\hline
\end{tabular}

Note: the parameters for cement paste casting with micelles solution was previously reported in [Hu et al. 2012a] 
relevant for the present investigation, mainly because of: 1) the type and size of the hereby PEO-b-PS - based vesicles, being in the nano-range; 2) these self-assembled architectures are in a minimal concentration of 0.025 wt. \% per cement weight. Moreover, the hydration of $\mathrm{C}_{3} \mathrm{~S}$ in specimens $\mathrm{OPCV}$ was only delayed for 36 minutes (Fig. 2(a)), whereas the reported retardation in $\mathrm{C}_{3} \mathrm{~S}$ hydration is in the range of 3-17 h (Sakai et al. 2006; Winnefeld et al. 2007), relevant to concentration of 0.1-0.5 wt. \% by cement weight (Sakai et al. 2006; Winnefeld et al. 2007; Yamada et al. 2000). However, dispersive effects can't be excluded and need further investigation, which is beyond the scope of this study and will be further reported.

\subsection{Microstructural alterations of cement paste in the presence of the admixed vesicles 3.2.1 Gel pore structure}

Nitrogen adsorption test, which is widely used for the investigation of the microstructure of cement-based materials (the pore size determined by nitrogen adsorption test is normally in the range from $1 \mathrm{~nm}$ to $300 \mathrm{~nm}$ ) (Aligizaki 2006; De Belie et al. 2010; Garci Juenger and Jennings 2001), was applied in this study to evaluate the influence of the admixed vesicles on the gel pores structure of cement paste (normally ranging from $0.5 \mathrm{~nm}$ to $0.01 \mu \mathrm{m}$ (Mindess and Young 1981). Figure 5 presents the total porosity and pore size distribution of both
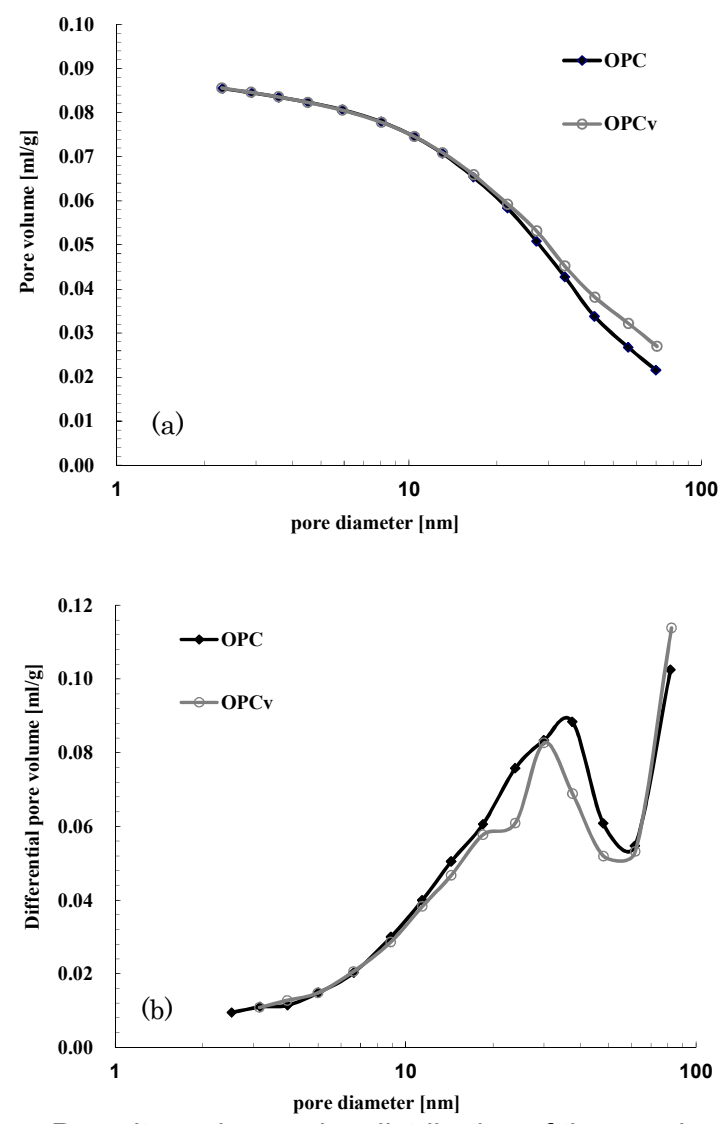

Fig.5 Porosity and pore size distribution of the specimens at 7 day hydration age, derived from $\mathrm{N}_{2}$ adsorption test. specimens at 7 day hydration age, derived from $\mathrm{N}_{2}$ adsorption tests (due to the limitation of the nitrogen adsorption tests, the determined pore size range was only from $3 \mathrm{~nm}$ to $80 \mathrm{~nm}$ in this study).

As seen from the plots, the total gel porosity was similar for both specimens OPC $(0.855 \mathrm{ml} / \mathrm{g})$ and $\mathrm{OPCv}$ $(0.856 \mathrm{ml} / \mathrm{g})$. The gel pores with large size (pore size range from 40-80 $\mathrm{nm}$ ) for specimen OPCv were slightly more pronounced than for specimen OPC (Fig. 5(a)). The critical pore size of the gel pores was also identical for both specimens OPC and OPCv, as shown in Fig. 5(b). From these results it is obvious that the gel pore structure of cement paste was not significantly influenced by the admixed vesicles.

\subsubsection{Capillary pore structure}

MIP, which can evaluate a much wider pore size range than $\mathrm{N}_{2}$ adsorption test (the pore size range determined by MIP was between $0.007 \mu \mathrm{m}$ and $350 \mu \mathrm{m}$ in the present study), was employed to investigate the microstructural alterations of cement paste in the presence of admixed vesicles.

The cumulative intruded volume curves (Fig. 6(a)) and differential distribution curves (Fig. 6(b)) derived from MIP at 7 days hydration age are shown in Fig. 6. At
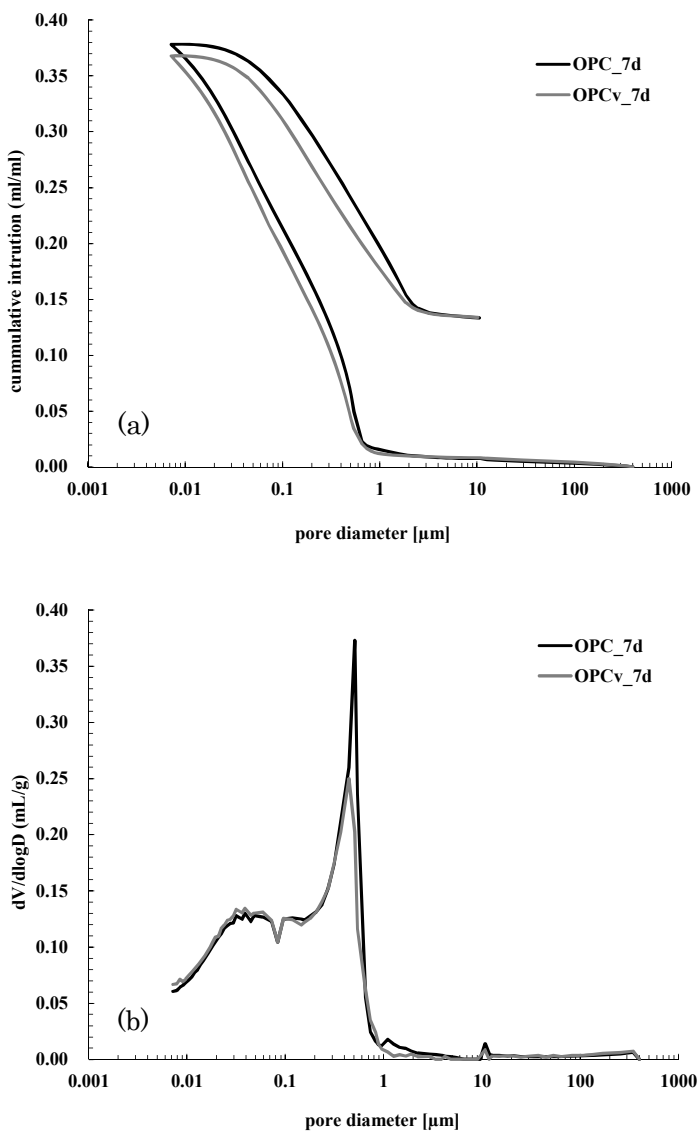

Fig. 6 Porosity and pore size distribution of the specimens at 7 day hydration age, derived from MIP test: (a) Cumulative intruded volume curves; (b) Differential distribution curves. 
7 days hydration age, the total porosity of cement paste was slightly reduced by the admixed vesicles: the total porosity was $36.78 \%$ for specimen $\mathrm{OPCV}$ and $37.81 \%$ for specimen OPC, Fig. 6(a). Further, it is observed in Fig. 6(b) that the critical pore size was similar for both specimens, which is as derived by $\mathrm{N}_{2}$ adsorption tests; however, the critical pore size for the capillary pores (normally ranging from $0.01 \mu \mathrm{m}$ to $10 \mu \mathrm{m}$ (Mindess and Young 1981)) decreased in the presence of the admixed vesicles $(0.44 \mu \mathrm{m}$ for specimen OPCv and $0.51 \mu \mathrm{m}$ for specimen OPC). Therefore, it can be stated that in the presence of admixed vesicles, the slightly denser pore structure and reduced critical pore size (which is the smallest pore size of a connected pore network) would result in reduced pore network connectivity (a similar effect was also observed in the presence of micelles, $(\mathrm{Hu}$ et al. 2012a). Therefore, if the vesicles are admixed in reinforced concrete, chloride penetration is expected to be halted, leading to a delay of corrosion initiation and further propagation on the steel reinforcement. Since on the other hand hydration rate and hydration degree were not affected or showing a slightly reversed trend (Figs. 3, 4), the observed microstructural alterations in the presence of admixed vesicles can only be related to their influence on the formation and distribution of hydration products, which will be discussed in what follows.

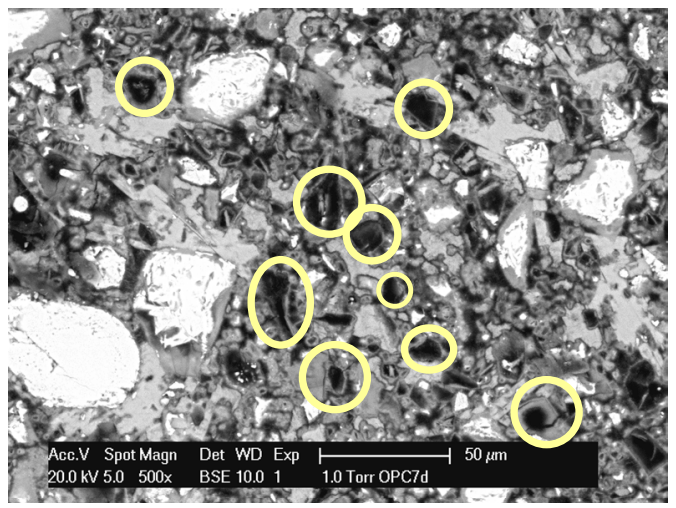

(a) Specimen OPC

\subsection{Distribution of hydration products in the presence of vesicles}

Figure 7 presents the morphology of the cement matrix for both specimens OPC and OPCV at the hydration age of 7 days (ESEM observation). Distinguishing the admixed vesicles in the cement matrix is impossible due to their nano-size, however, their influence on the development of the bulk microstructure is obvious: the cement matrix was denser for specimen OPCv (Fig. 7(b)), compared to specimen OPC (Fig. 7(a)), presenting significantly lower amount of pores in the former and higher amount in the latter case (pore space indicated as circled areas in Fig. 7). Further, the distribution of hydration products was also altered in the presence of vesicles: for specimen OPC, the hydration products were predominantly formed around the un-hydrated cement particles (high density CSH (Jennings 2000; Richardson 1999)), whereas for specimen OPCv visually higher amount of hydration products were observed in the bulk matrix (low density CSH (Jennings 2000; Richardson 1999)).

Nano indentation tests confirmed these observations. Figure 8 presents the ESEM images (magnification of $500 \times$ ) and maps of elastic modulus $E$ of the test area in cement paste for both specimens. The nano indentation test was conducted in the area between two adjacent un-hydrated cement particles, which is marked as the

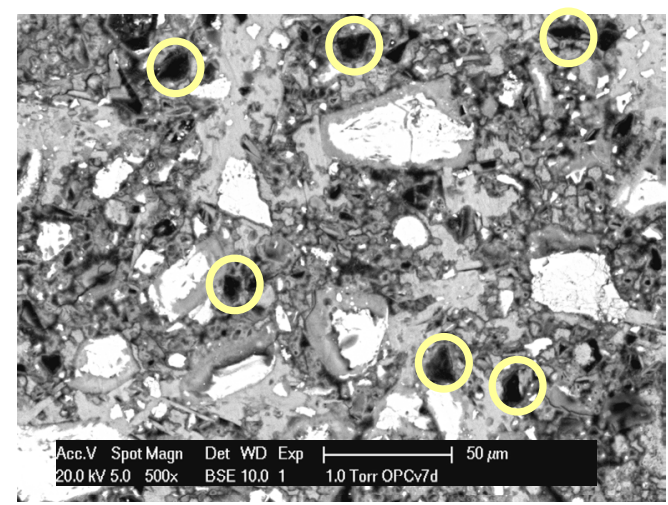

(b) Specimen OPCV

Fig.7 ESEM images (a) OPC; (b) OPCv both at 500× magnification at 7 days hydration age.

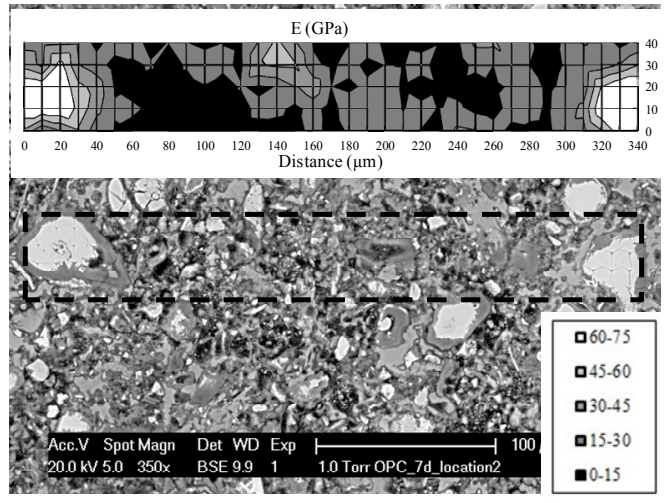

(a) OCP

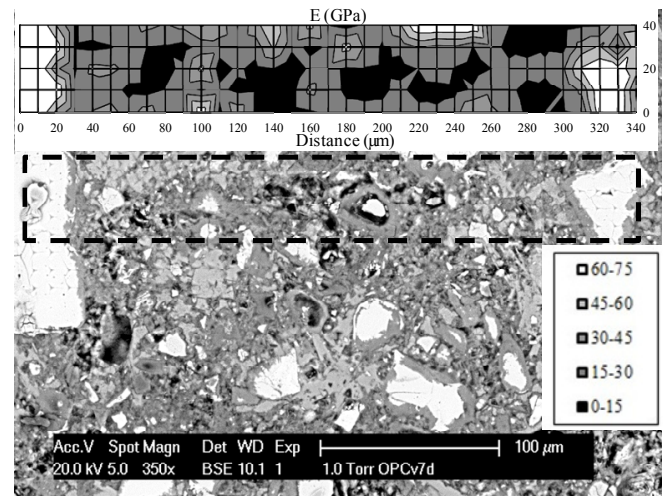

(b) $\mathrm{OPCV}$

Fig.8 Maps of elastic modulus $\mathrm{E}$ of the test area in cement paste, together with the corresponding ESEM images (marked rectangular areas corresponds to the modulus maps). 
rectangular area in the corresponding ESEM images. As well known, the CSH gel in cement paste can be classified into two different morphological forms (Jennings 2000; Richardson 1999): high density (HD) CSH with an elastic modulus values in the range of 29.1-31.4 GPa and low density (LD) CSH with an elastic modulus values in the range of 18.2-23.4 GPa (Constantinides and Ulm 2004; Constantinides et al. 2003; Zhu et al. 2007).

These two distinct phases are also characteristic in this study. The influence of admixed vesicles on the formation of HD CSH was not obvious, confirmed by the similar distribution of modulus value between 30 and 45
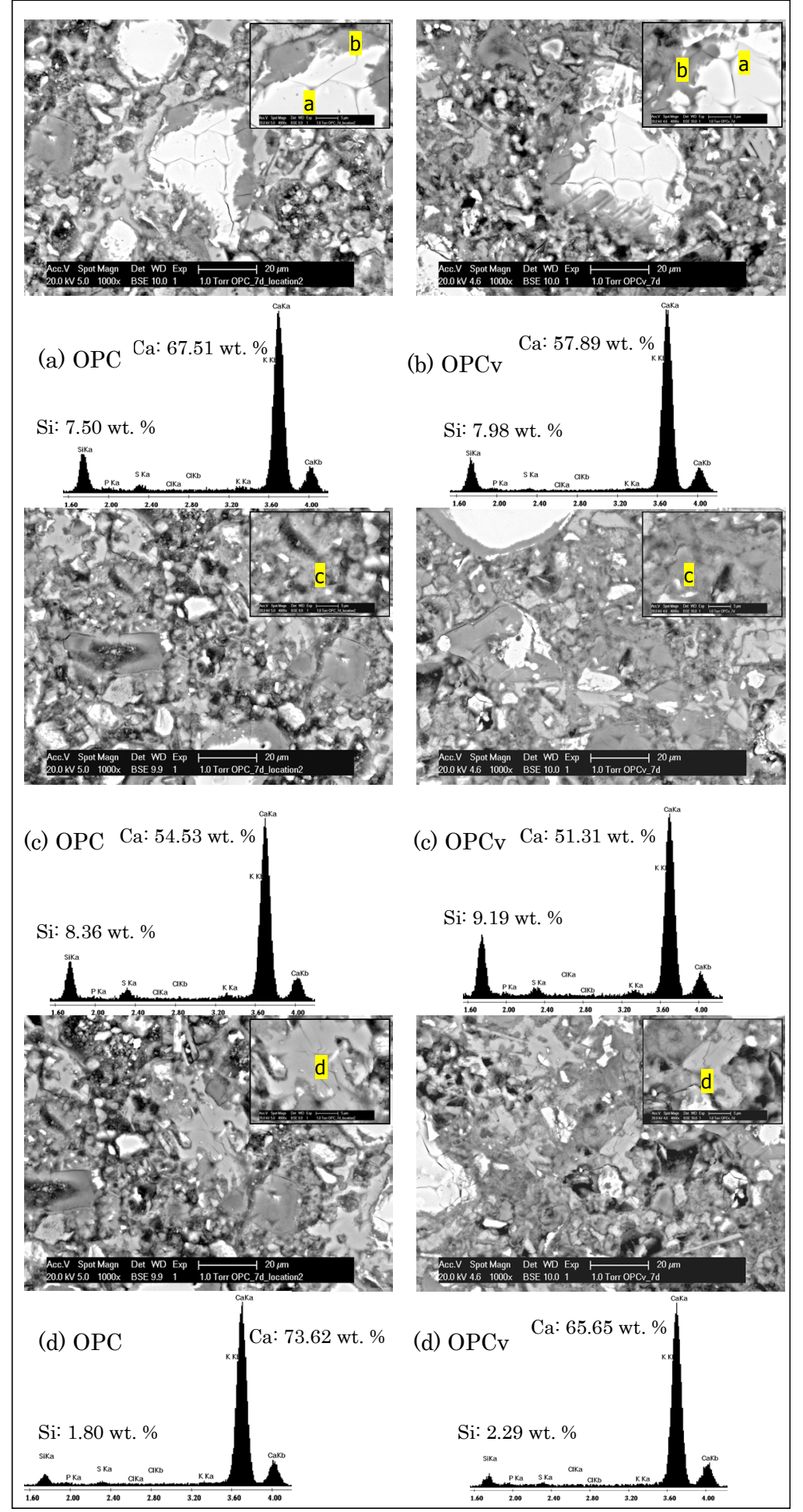

Fig.9 ESEM images and the corresponding EDX pattern for: (a) un-hydrated cement grains, (b) HD CSH, (c) LD CSH and (d) $\mathrm{CH}$ ) in OPC (left column) and OPCv (right column)

(the test points - nano-indents - are well visible in the images of un-hydrated grains) 
$\mathrm{GPa}$ for both specimens (the percentage of nano indents with a modulus value between 30 and $45 \mathrm{GPa}$ was $9.71 \%$ for specimen $\mathrm{OPC}$ and $10.86 \%$ for specimen $\mathrm{OPCV}$ respectively in Fig. 8). However, the distribution of LD CSH was significantly altered in the presence of vesicles: for specimen $\mathrm{OPCv}$, a larger area corresponding to LD $\mathrm{CSH}$ (the percentage of nano indents with a modulus value between 15 and $30 \mathrm{GPa}$ was $25.14 \%$ for specimen OPCv, compared to $21.14 \%$ for specimen OPC) was observed; the area corresponding to the pores in the cement matrix was also larger for specimen OPC (the percentage of nano indents with a modulus value between 0 and $15 \mathrm{GPa}$ was $41.71 \%$ for specimen OPC, compared to $34.29 \%$ for specimen OPCv). The results indicate that the admixed vesicles lead to a more uniform distribution of low density hydration products and a more homogeneous and denser cement matrix (a result, which was also observed previously in the presence of micelles, (Hu et al. 2012a)) .

Figure 9 presents ESEM images (in BSE mode), emphasizing on different phases ((a) un-hydrated cement particle (UH), (b) HD CSH, (c) LD CSH and (d) $\mathrm{CH}$ ) and the corresponding EDX analysis (the test points are also marked in the images) for specimen OPC after the nano indentation test. Well known is that the different mineral phases in a cement matrix exhibit different grey levels in the BSE images. Skedros et al. (1993) and Ye (2003) demonstrated that the grey-scale level in BSE images corresponds to the average atomic number and mineral density of each phase. Based on these well-known dependencies and considering the BSE images obtained in the present study, the main mineral phases in both OPC and $\mathrm{OPCv}$ can be distinguished by the order of grey-scale intensity values as follows: $\mathrm{UC}>\mathrm{CH}>\mathrm{HD} \mathrm{CSH}>\mathrm{LD}$ $\mathrm{CSH}>$ pore structures.

EDX analysis indicates the presence of $\mathrm{Ca}$ and $\mathrm{Si}$ for the different mineral phases (Fig. 9) (EDX analysis was performed as qualification and semi-quantification only; no absolute values are claimed in this study, but rather relevant contents via peaks intensity for equal current/voltage characteristics of the beam and live seconds of investigation). Based on the combination of the nano indentation tests (the nano indents can be easily observed

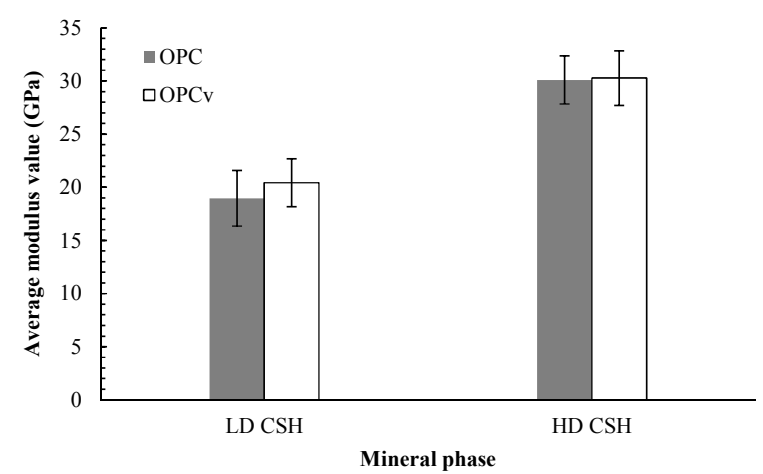

Fig.10 Average indentation modulus values of both LD $\mathrm{CSH}$ and $\mathrm{HD} \mathrm{CSH}$ in the cement paste for specimen OPC and OPCV. in the ESEM images after the tests, as shown in Fig. 9, top row), ESEM images and EDX analysis, the phase on which each nano indent contacted the matrix can be easily determined. Therefore, with a large number of indentation data (the number of total nano indents was more than 1000 for both specimens), the average indentation modulus values of HD CSH and LD CSH for both specimens were calculated by statistical analysis, the average values as shown in Fig. 10.

The calculated average modulus of the individual mineral phases further confirms the nano indentation mapping results: the modulus value of HD CSH was not influenced by the admixed vesicles; the modulus value of LD CSH was slightly higher in the presence of vesicles. Because the mechanical properties of the LD CSH and HD CSH are intrinsic to cement paste (Constantinides and Ulm 2004; Constantinides et al. 2003; Zhu et al. 2007), the most plausible reason for the lower modulus value of LD CSH for specimen OPC is related to a more porous microstructure of the cement matrix. As afore-mentioned in the "Introduction" section, the PEO-containing polymers influence the properties of fresh cement paste: they can hinder the coagulation and sedimentation of un-hydrated cement particles by increasing the electrostatic and/or steric repulsive forces (Jansen et al. 2012; Mollah et al. 2000). This effect would influence the distribution of hydration products in the hardened cement paste. Further, as reported (Nicoleau 2010), PEO-containing polymers can act as nucleation sites for the formation of new hydration products. In this study, considering that the here investigated vesicles contain -PEO- architectures, similar effects are to be expected: dispersion effects together with "nucleation effects" would contribute to a more uniform distribution of hydration products and a denser pore network in the presence of admixed vesicles.

\section{Conclusions}

The hydration process and microstructure alterations of cement paste in the presence of admixed poly(ethylene oxide)-block-polystyrene $\left(\mathrm{PEO}_{113}-\mathrm{b}-\mathrm{PS}_{780}\right)$ vesicles at early hydration age were investigated. The results indicate that at early hydration age, the admixed vesicles slightly retard the hydration rate of the cement paste, evidenced by isothermal calorimetry and non-evaporable water content tests. The admixed vesicles did not significantly change the gel pore structure of the cement matrix, which is consistent with the slightly retarded hydration rate. This observation is in contrast to the opposite trend, previously observed and reported for PEO-b-PS micelles and is denoted to the larger surface area of the latter (core-shell structure of $50 \mathrm{~nm}$ ), compared to the former (nano-sacs of $220 \mathrm{~nm}$ ). However, at the stage of 7 days, a denser capillary pore structure was observed in the presence of the here investigated vesicles. Nano indentation tests confirmed micro-mechanical alterations and proved that the admixed vesicles act as 
nucleation sites, leading to a more uniform distribution of low density hydration products. An additional, plausible mechanism could be related to initial dispersion effects on the un-hydrated cement particles and is subject to on-going research (including zeta-potential alterations) in the presence of vesicles.

\section{Acknowledgement}

This work has been performed in the frame of IOP project 08743 , financed by Agentschap NL and supported by TU Delft and within the postdoctoral research of the first author in TU Delft, Faculty CiTG, department M\&E, The Netherlands.

\section{References}

Aitcin, P. C. and Neville A., (2003). "How the water-cement ratio affects concrete strength." Concrete International, 25(8), 51-58.

Aligizaki, K. K., (2006). "Pore structure of cement-based materials: Testing interpretation and requirements." Taylor \& Francis.

Barrett, E. P., Joyner, L. G. and Halenda, P. P., (1951). "The determination of pore volume and area distributions in porous substances. I. Computations from nitrogen isotherms." Journal of the American Chemical society, 73(1), 373-380.

Chandra, S. and Flodin, P., (1987). "Interactions of polymers and organic admixtures on portland cement hydration." Cement and Concrete Research, 17(6), 875-890.

Constantinides, G., Ulm, F. J. and Van Vliet, K., (2003). "On the use of nanoindentation for cementitious materials." Materials and structures, 36(3), 191-196.

Constantinides, G. and Ulm, F. J., (2004). "The effect of two types of $\mathrm{CSH}$ on the elasticity of cement-based materials: Results from nanoindentation and micromechanical modeling." Cement and Concrete Research, 34(1), 67-80.

Copeland, L. E. and Hayes, J. C., (1953). "The determination of non-evaporable water in hardened portland cement paste." ASTM Bull., 194, 70-74.

De Belie, N., Kratky, J. and Van Vlierberghe, S. (2010). "Influence of pozzolans and slag on the microstructure of partially carbonated cement paste by means of water vapour and nitrogen sorption experiments and BET calculations." Cement and Concrete Research, 40(12), 1723-1733.

Folliard, K. J. and Berke, N. S., (1997). "Properties of high-performance concrete containing shrinkage-reducing admixture." Cement and Concrete Research, 27(9) , 1357-1364.

Garci, Juenger, M. C. and Jennings, H. M. (2001). "The use of nitrogen adsorption to assess the microstructure of cement paste." Cement and Concrete Research, 31(6), 883-892.

Gil, E. S. and Hudson, S. M., (2004). "Stimuli-reponsive polymers and their bioconjugates." Progress in polymer science, 29(12), 1173-1222.
Girod, M., Phan, T. N. T. and Charles, L., (2008). "Microstructural study of a nitroxide-mediated poly (ethylene oxide) / polystyrene block copolymer (PEO-b-PS) by electrospray tandem mass spectrometry." Journal of the American Society for Mass Spectrometry, 19(8), 1163-1175.

Gorna, K., Muñoz, Espí R., Gröhn, F. and Wegner, G., (2007). "Bioinspired mineralization of inorganics from aqueous media controlled by synthetic polymers." Macromolecular bioscience, 7(2), 163-173.

Gu, P., Xie, P., Beaudoin, J. J. and Jolicoeur, C., (1994). "Investigation of the retarding effect of superplasticizers on cement hydration by impedance spectroscopy and other methods." Cement and Concrete Research, 24(3), 433-442.

Hadjichristidis, N., Pispas, S. and Floudas, G. A., (2002). "Block copolymers: synthetic strategies, physical properties, and applications." Wiley-Interscience: New York

Hamley, I. W., (1998). "The physics of block copolymers." Oxford University Press, Oxford.

Hu, J., Koleva, D. A., De Wit, J. H. W., Kolev, H. and Van Breugel, K., (2011). "Corrosion performance of carbon steel in simulated pore solution in the presence of micelles." Journal of the Electrochemical Society, 158, C76-C87.

Hu, J., Koleva, D., Ma, Y., Schlangen, E., Petrov, P. and Van Breugel, K., (2012a). "The influence of admixed micelles on the microstructural properties and global performance of cement-based materials." Cement and Concrete Research, 42,1122-1133.

Hu, J., Koleva, D. and Van Breugel, K., (2012b). "Corrosion performance of reinforced mortar in the presence of polymeric nano-aggregates: electrochemical behavior, surface analysis, and properties of the steel/cement paste interface." Journal of materials science, 47(12), 4981-4995.

Hu, J., Koleva, D. A., Petrov, P. and van Breugel, K. (2012c). "Polymeric vesicles for corrosion control in reinforced mortar: electrochemical behavior, steel surface analysis and bulk matrix properties." Corrosion science, 65, 414-430.

Hu, J., Koleva, D.A. and Van Breugel, K. (2012d). "The influence of PEO113-b-PS780 vesicles on the corrosion performance of carbon steel in simulated pore solution." ECS Trans, 41(16), 1-9.

Jansen, D., Neubauer, J., Goetz-Neunhoeffer, F., Haerzschel, R. and Hergeth, W.D., (2012). "Change in reaction kinetics of a Portland cement caused by a superplasticizer-Calculation of heat flow curves from XRD data." Cement and Concrete Research, 42, 327-332.

Jennings, H. M., (2000). “A model for the microstructure of calcium silicate hydrate in cement paste." Cement and Concrete Research, 30(1), 101-116.

Khanal, A. and Nakashima, K., (2005). "Incorporation and release of cloxacillin sodium in micelles of poly 
(styrene-b-2-vinyl pyridine-b-ethylene oxide)." Journal of controlled release, 108(1), 150-160.

Kojima, H., Yoshihara, K., Sawada, T., Kondo, H. and Sako, K., (2008). "Extended release of a large amount of highly water-soluble diltiazem hydrochloride by utilizing counter polymer in polyethylene oxides (PEO)/polyethylene glycol (PEG) matrix tablets." European Journal of Pharmaceutics and Biopharmaceutics, 70(2), 556-562.

Krishnamoorti, R., Rai, S. and Hammouda, B., (1998). "Phase behavior of block copolymer blends." APS March Meeting Abstracts.

Li, C. Z., Feng, N. Q., Li, Y. D. and Chen, R. J., (2005). "Effects of polyethlene oxide chains on the performance of polycarboxylate-type water-reducers." Cement and Concrete Research, 35(5), 867-873.

Lothenbach, B., Winnefeld, F. and Fig. i, R., (2007). "The influence of superplasticizers on the hydration of Portland cement." Proceedings of the 12th ICCC 2007, Montreal, Canada.

Matyjaszewski, K. and Xia, J., (2001). “Atom transfer radical polymerization." Chemical Reviews, 101(9), 2921-2990.

Merlin, F., Guitouni, H., Mouhoubi, H., Mariot, S., Vallée, F. and Van Damme, H., (2005). "Adsorption and heterocoagulation of nonionic surfactants and latex particles on cement hydrates." Journal of colloid and interface science, 281(1), 1-10.

Mindess, S. and Young, J. F. (1981). "Concrete." Prentice Hall, Englewood Cliffs, NJ.

Molina, L., (1992). "On predicting the influence of curing conditions on the degree of hydration." $C B I$ Report 5:92. Stockholm, Swedish Cement and Concrete Research Institute, Stockholm.

Mollah, M., Adams, W., Schennach, R. and Cocke, D., (2000). "A review of cement-superplasticizer interactions and their models." Advances in Cement Research, 12(4), 153-161.

Neville, A. and Aitcin, P. C., (1998). "High performance concrete - an overview." Materials and Structures, 31(2), 111-117.

Oliver, W. C. and Pharr, G. M. (2004). "Measurement of hardness and elastic modulus by instrumented indentation: Advances in understanding and refinements to methodology." Journal of Materials Research, 19(01), 3-20.

Park, C., Yoon, J. and Thomas, E. L., (2003). "Enabling nanotechnology with self assembled block copolymer patterns." Polymer, 44(22), 6725-6760.

Pourchet, S., Comparet, C., Nicoleau, L. and Nonat, A., (2007). "Influence of PC superplasticizers on tricalcium silicate hydration." Proceedings of the 12 th International Congress on the Chemistry of Cement, Montreal, Canada, 2007.

Richardson, I., (1999). "The nature of CSH in hardened cements." Cement and Concrete Research, 29(8), 1131-1147.

Rudloff, J., Antonietti, M., Cölfen, H., Pretula, J.,
Kaluzynski, K. and Penczek, S., (2002). "Double-hydrophilic block copolymers with monophosphate ester moieties as crystal growth modifiers of $\mathrm{CaCO}_{3}$." Macromolecular Chemistry and Physics, 203(4), 627-635.

Sakai, E., Kasuga, T., Sugiyama, T., Asaga, K. and Daimon, M., (2006). "Influence of superplasticizers on the hydration of cement and the pore structure of hardened cement." Cement and Concrete Research, 36(11), 2049-2053.

Singh, M., Odusanya, O., Wilmes, G. M., Eitouni, H. B., Gomez, E. D., Patel, A. J., Chen, V. L., Park, M. J., Fragouli, P. and Iatrou, H., (2007). "Effect of molecular weight on the mechanical and electrical properties of block copolymer electrolytes." Macromolecules, 40(13), 4578-4585.

Skedros, J. G., Bloebaum, R. D., Bachus, K. N., Boyce, T. M. and Constantz, B., (1993). "Influence of mineral content and composition on graylevels in backscattered electron images of bone." Journal of biomedical materials research, 27(1), 57-64.

Sun, Z. and Gutmann, J. S., (2004). "Synthesis of TiO2 nanoparticles in ultrathin block copolymer films-an integral geometry study." Physica A: Statistical Mechanics and its Applications, 339(1), 80-85.

Uchikawa, H., Hanehara, S. and Sawaki, D., (1997). "The role of steric repulsive force in the dispersion of cement particles in fresh paste prepared with organic admixture." Cement and Concrete Research, 27(1), 37-50.

Washburn, E. W., (1921). "The dynamics of capillary flow." Physical review, 17(3), 273.

Winnefeld, F., Becker, S., Pakusch, J. and Götz, T., (2007). "Effects of the molecular architecture of comb-shaped superplasticizers on their performance in cementitious systems." Cement and Concrete Composites, 29(4), 251-262.

Yamada, K., Takahashi, T., Hanehara, S. and Matsuhisa, M. (2000). "Effects of the chemical structure on the properties of polycarboxylate-type superplasticizer." Cement and Concrete Research, 30(2), 197-207.

Ye, G., (2003). "Experimental study and numerical simulation of the development of the microstructure and permeability of cementitious materials." Ph.D. thesis. Delft: Delft University of Technology.

Young, J., (1972). "A review of the mechanisms of set-retardation in Portland cement pastes containing organic admixtures." Cement and Concrete Research, 2(4), 415-433.

Zhang, T., Shang, S., Yin, F., Aishah, A., Salmiah, A. and Ooi, T., (2001). "Adsorptive behavior of surfactants on surface of Portland cement." Cement and Concrete Research, 31(7), 1009-1015.

Zhu, W., Hughes, J. J., Bicanic, N. and Pearc,e C. J., (2007). "Nanoindentation mapping of mechanical properties of cement paste and natural rocks." Materials characterization, 58(11), 1189-1198. 